\title{
INTERCRYSTALLINE BRITTLENESS OF LEAD
}

By Henry S. Rawdon

CONTENTS

II. Corroded lead sheathing $\ldots \ldots \ldots \ldots \ldots$

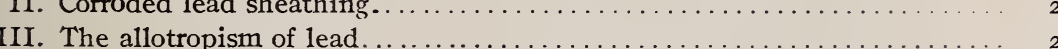

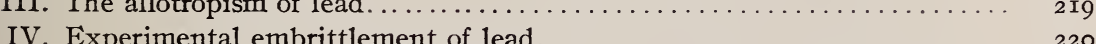

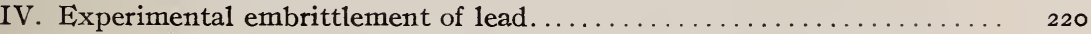

I. Immersion in solutions of lead salts................... 220

2. Electrolysis of lead in concentrated nitric acid . . . . . . . . 228

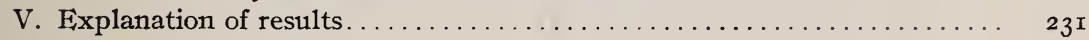

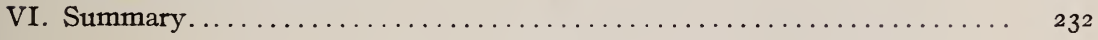

\section{INTRODUCTION}

The relation between the course or the path of the fracture of metals and alloys produced in service or as a result of certain laboratory tests and the crystalline units of which such materials are composed is of utmost importance. The fracture of normal material is, in general, intracrystalline; that is, it consists of a break across the grains rather than of a separation between them. An intercrystalline fracture indicates either that the metal is of very inferior quality or that the break occurred under very unusual conditions; for example, at a very high temperature. The usual mechanical tests, when applied to metals of the type which breaks with an intercrystalline fracture, merely measure the coherence of adjacent grains for one another and reveal little as to the real properties of the metal itself.

Even such a soft, plastic substance as lead, under suitable conditions, may be rendered so weak and brittle that it can be easily crumbled into powder by the fingers, although the constituent grains have lost none of the intrinsic properties of lead. Various erroneous explanations of this behavior of lead have appeared in the scientific literature, the change being described usually as an allotropic one. The importance, in an industrial sense, of a proper explanation of this type of the corrosion of lead justifies the description of the type of metal deterioration which follows. 


\section{CORRODED LEAD SHEATHING}

In Figs. I and 2 are shown two typical specimens of corroded lead sheathing selected from materials submitted to the Bureau for examination. Fig. I shows a section of the sheathing of an aerial cable; Fig. 2, that of the lead covering of a subterranean feeder line of an electric-light system. In this case the deterio-

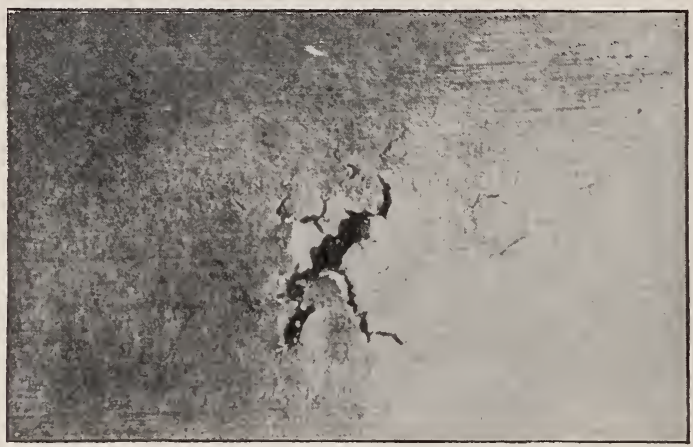

(a) Unetched, surface view. $\times_{3}$

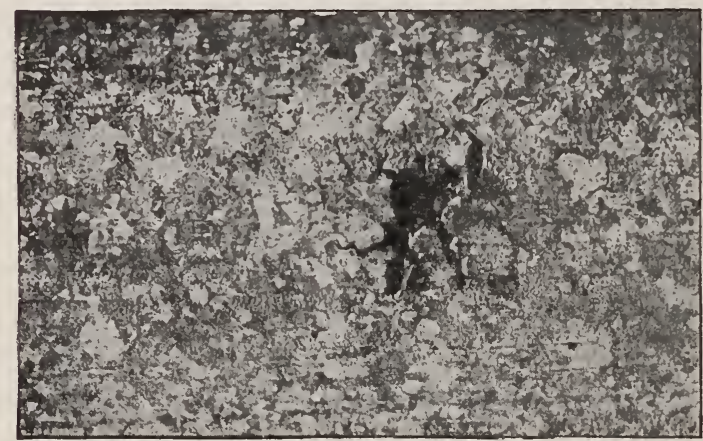

(b) Same material, etched with concentrated nitric acid. $\times_{3}$

FIG. I. Intercrystalline brittleness in commercial lead

The material was part of the covering of an aerial cable; the details of service were not reported, other than that it occurred in a hot climate. The break may have been the result of the combined effect of stress and corrosion

ration had proceeded to a much greater extent than in the case shown in Fig. I, so that certain portions of the metal could easily be crumbled into a coarse, gray powder by the fingers. This was true, in particular, of those portions of the sheathing where the surface discoloration showed it to have been immersed in water. The surface appearance of the embrittled lead is shown in Fig. 3. The sheathing in such spots was so weak and brittle that it could be easily crumbled into a gray powder, although the 
appearance of the original surface was but little changed. In Fig. $4 a$ some of the particles of the embrittled lead are shown, many of which are of a definite crystalline form. Each particle,

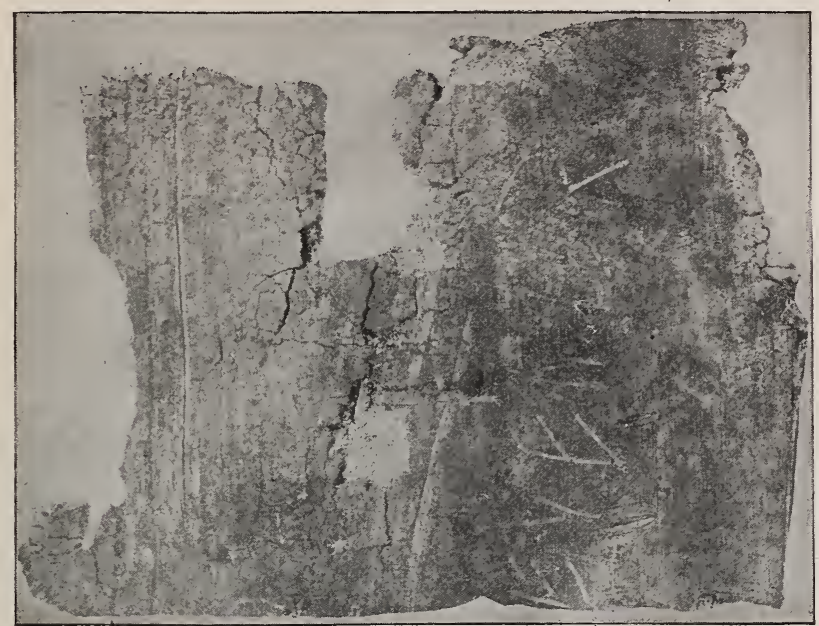

FIG. 2.-Corroded lead-cable sheaihing

A portion of the embrittled cable sheathing was flattened out. The photograph shows the exterior of the sheath; the surface has been broken up by a network of "alligator cracks." The metal can be easily crumbled with the fingers. One-half natural size

when tested on a glass plate with a small pestle, was found very malleable, and when cut the characteristic color of lead was

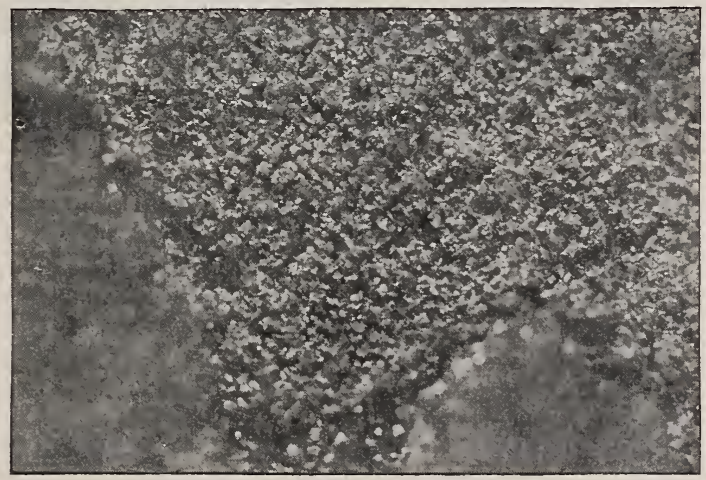

FIG. 3.-Corroded lead-cable sheathing

The small granular spot in Fig. 2 is here shown at a higher magnification. The rough crystalline appearance of the metal is very evident. $\times 8$

revealed. That the lead was still malleable was illustrated by rolling portions of the embrittled lead into thin strips. By suitable care the metal was rolled as thin as 0.008 inch; however, 
the metal tore badly during the rolling, as shown in Fig. $4 b$. Evidently the coherence of crystals for each other comprising the lead sheathing had been greatly weakened, but the crystals themselves still retained the characteristic properties of lead.

In Fig. 5 is shown the appearance of a cross section of the sheathing. This was taken from a portion in which the metal was only, partially embrittled. That the method of the corrosive

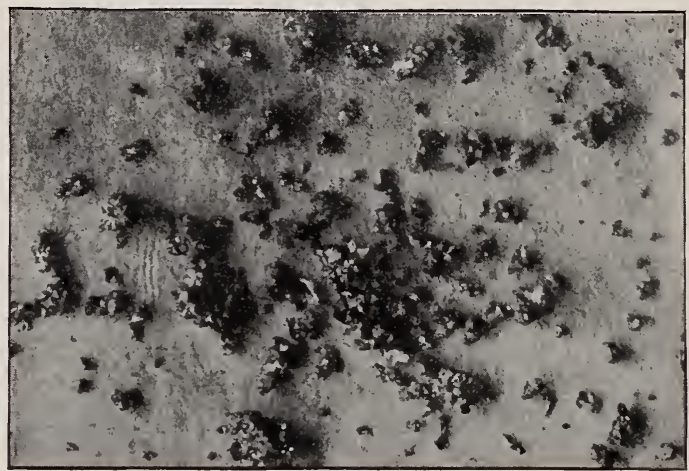

(a)

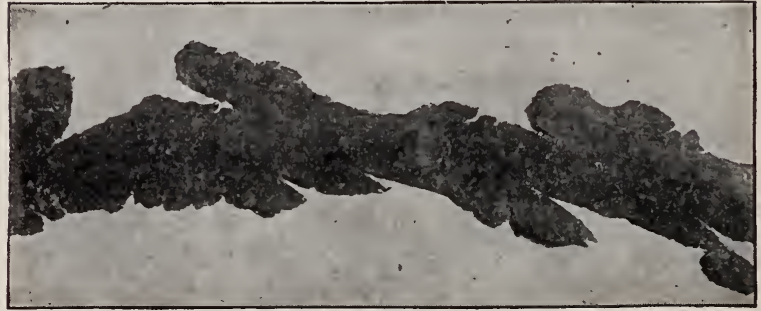

(b)

FIG. 4.-Corroded lead-cable sheathing

(a) The corroded metal can be easily crumbled into small grains as shown. Many of the grains show definite crystalline faces. $\times 8$

(b) The grains composing embrittled lead are still malleable. Pieces can be rolled into thin sheets if care is taken. The strips tear badly in rolling, however. Above strip was reduced from 0.12 to 0.008 inch in thickness. $X I$

attack is intercrystalline in its nature, as well as the fact that the action begins on the outer or exposed surface of the sheathing and proceeds inwardly, is very evident from the micrograph shown in Fig. 5 .

A chemical analysis of the material showed that there was no essential difference between the corroded and the uncorroded portions and that the lead contained a considerable amount of tin. A determination of the melting point of the material con- 
firmed the indications of the chemical analysis that the embrittled portions of the lead are essentially the same as the unattacked parts. These data are summarized in Table I below:

TABLE 1.-Composition and Melting Point of Embrittled Lead

\begin{tabular}{|c|c|c|}
\hline & $\underset{\text { portion }}{\text { Embrittled }}$ & $\begin{array}{l}\text { Unattacked } \\
\text { portion }\end{array}$ \\
\hline & Per cent & Per cent \\
\hline Tin.. & 1.09 & 1.06 \\
\hline Lead.. & 98.3 & 98.28 \\
\hline Melting point. & $325.4^{\circ} \mathrm{C}$ & $325.6^{\circ} \mathrm{C}$ \\
\hline
\end{tabular}

The melting point of pure lead is $327.4^{\circ} \mathrm{C}\left(62 \mathrm{I} .3^{\circ} \mathrm{F}\right)$.

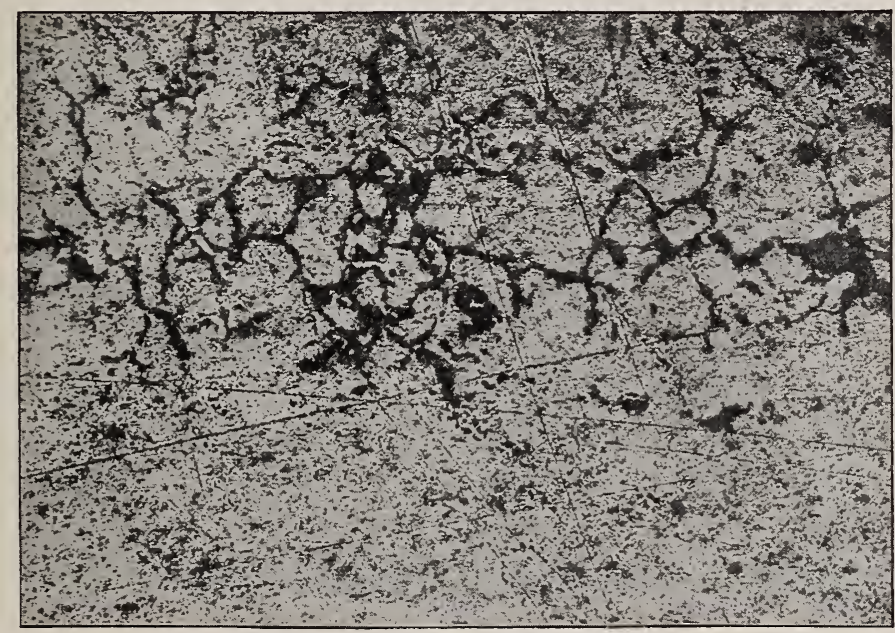

FIG. 5.-Corroded lead sheathing

Cross section through a portion of material of Fig. 2. which was only partially cmbrittled. The action begins at the outside and the intercrystalline metal is first attacked. Specimon is unetched. $\times 5^{\circ}$

\section{ALLOTROPISM OF LEAD}

An allotropic form of lead similar in its properties to the wellknown "gray tin" has been described by Heller ${ }^{1}$. Creighton ${ }^{2}$ has described a method entirely different from that used by Heller, by which this "gray lead" appeared to be produced. In brief, Heller's method consisted in the immersion of bright sheets of lead in solutions of lead acetate which contained appreciable amounts of nitric acid. The transition was stated to have begun at the end of two days and to have been complete in about three

\footnotetext{
${ }^{1}$ Hans Heller, Zeit. f. Phys. Chem., 89, p. 76r; 1915.

${ }^{2}$ H. J. M. Creighton, Jour. Am. Chem. Soc., 37, p. 2064; 1915.
} 
weeks. The lead lost its original strength and ductility and disintegrated into particles, gray to gray black in color, which could be pressed easily between the fingers into a pulverulent mass. The change was stated to occur to a very slight extent in lead immersed in solutions of pure lead acetate. The addition of a small amount of nitric acid, however, increased the rate of change very markedly. Lead solutions other than that of the acetate were found to permit the change to occur. However, the presence of a small amount of nitric acid appeared to be necessary in every case. The inoculation of pure sheet lead with some of the gray form did not lead to any detectable change in the inoculated specimen. The lead used throughout the experiments was described as not containing "other metals in amounts worth mentioning. Neither silver nor tin was present, and only a trace of iron was found."

The method described by Creighton consisted in the electrolysis of lead in nitric acid (sp gr, I.42), the lead being the cathode. The cathode was described as having increased slightly in volume and having lost its former malleability and firmness. The lower portion was found to have been completely changed. Small particles which could easily be detached could be rubbed into a fine powder or pressed together into a soft mass. Cohen and Helderman ${ }^{3}$ have noted changes in the density of clean lead filings immersed for about three weeks in a lead-acetate solution, and have interpreted the density changes as evidence of an allotropic change occurring within the lead. An immersion of three weeks caused an increase in density from I I.322 to I I.342. Heating the lead after immersion has the effect of slightly lowering the density. These changes are, however, very much less in magnitude than those described by both Heller and Creighton.

\section{EXPERIMENTAL EMBRITTLEMENT OF LEAD}

The method described by Heller and Creighton, by which the allotropic forms of lead may be produced, was tested out for the purpose of comparing the granular lead which may result from corrosion during service with the allotropic form.

\section{IMMERSION IN SOLUTIONS OF LEAD SALTS}

In the description of the method given by Heller lead-acetate solutions were used for most of the immersions, as was also done by Cohen and Helderman. In the preliminary trials a solution

${ }^{3}$ E. Cohen and WV. D. Helderman, Verslag K. Akad, Wetenschappen, 23, pp. 754-76r; 19I4. 
similar to that described by Heller was used: Water, $1000 \mathrm{~cm}^{3}$; lead acetate, $400 \mathrm{~g}$; nitric acid (sp gr, I.I6), $100 \mathrm{~cm}^{3}$. However, in most of the experiments normal solutions of neutral lead acetate were used, and the concentration of nitric acid was varied in different tests from $0.5 \mathrm{~N}$ to $2 \mathrm{~N}$.

Two types of lead were used, a commercial lead of ordinary grade and a pure lead of exceptionally high purity. The composition of the two grades is given in Table 2 .

TABLE 2.-Composition of Lead Used $a$

\begin{tabular}{|c|c|c|c|c|c|}
\hline Constituents & $\begin{array}{l}\text { Commer- } \\
\text { cial lead }\end{array}$ & $\begin{array}{l}\text { Iigh- } \\
\text { grade } \\
\text { lead }\end{array}$ & Constituents & $\begin{array}{l}\text { Commer- } \\
\text { cial lead }\end{array}$ & $\begin{array}{l}\text { High- - } \\
\text { grade } \\
\text { lead }\end{array}$ \\
\hline Antimony... & $\begin{array}{r}\text { Per cent } \\
0.07\end{array}$ & $\begin{array}{r}\text { Per cent } b \\
0.003\end{array}$ & Zinc........ & $\begin{array}{c}\text { Per cent } \\
\text { (c) }\end{array}$ & $\begin{array}{c}\text { Per cent } b \\
(c)\end{array}$ \\
\hline Iron.......... & .02 & .004 & Bismuth... & & (c) \\
\hline Tin...... & .14 & (c) & Silver....... & ........... & (c) \\
\hline Copper..... & (c) & (c) & Lead.......................... & 99.72 & $d 99.993$ \\
\hline Nickel... & (c) & (c) & & & \\
\hline
\end{tabular}

$a$ The author is indebtel to J. A. Scherrer, of this Bureau, for these analyses, as well as for the succeeding one (p. 229)

$b$ The analysis was carried out upon a sample of roo $\mathrm{g}$.

$c$ Not detected.

$d$ By difference.

In the series of tests described below thin sheets of pure lead 2 by $4 \mathrm{~cm}$ by $\mathrm{I} .5 \mathrm{~mm}$ were immersed in the different solutions for 24 days. In order to relieve any internal stresses set up by the cold rolling, which might influence the behavior of the lead when immersed in the electrolyte, the lead was annealed before use for approximately three hours at $200^{\circ} \mathrm{C}$ after being rolled into sheets.

The following solutions were used, and the specimens were suspended vertically by means of silk thread, so as to be exposed to the solution on all sides:

(I) $N$ lead acetate, $2 N$ nitric acid.

(2) $N$ lead acetate, r. $6 N$ nitric acid.

(3) $N$ lead acetate, $0.8 N$ nitric acid.

(4) $N$ lead acetate, $0.5 N$ nitric acid.

(5) $N$ lead acetate, no nitric acid.

(6) $N$ lead acetate, i.6 $N$ nitric acid.

The commercial-lead sheet was immersed in solution No. 6 and pure lead in each of the others. A volume of $50 \mathrm{~cm}^{3}$ of solution was used for each specimen. In all cases in which nitric acid was used a slight evolution of gas occurred, particularly in the first part of the test period. This was identified as nitric $160847^{\circ}-20-2$ 
oxide. The evolution of the gas from the pure lead immersed in solution No. 2 ( $N$ lead acetate and r.6 $N$ nitric acid) was at the approximate rate of $20 \mathrm{~cm}^{3}$ in 24 hours. When the commercial lead was immersed, the evolution was considerably faster. With solutions containing less nitric acid the evolution of gas was progressively less as the concentration of the acid was decreased. It could hardly be detected in the $0.5 \mathrm{~N}$ nitric-acid solution, and none whatever was observed in the solution of lead acetate to which no acid had been added.

A slight deposit or "sludge" formed in the bottom of the flask as the action of the solution upon the lead proceeded. In the cases where pure lead was used the amount was very small and increased in amount as the concentration of acid increased. The deterioration was most rapid in the case of the commercial lead, and a relatively large amount of sludge formed. Pure lead immersed in solution No. 2 ( $N$ lead acetate, r.6 $N$ nitric acid) gave $0.02 \mathrm{~g}$ deposit after 5 days' (24 hours each) immersion, while commercial lead in the same solution produced $0.5^{2} \mathrm{~g}$ in the same time. The sludge produced from the commercial lead contained some rather large-sized particles, similar to those shown in Fig. $4 a$, which were malleable and could be flattened out on a sheet of glass. (See Figs. $7 b$ and $7 c$.) The solution continued to act upon these particles, as was indicated by the evolution of the gas, and finally only a gray flocculent powder remained. The sludge formed from the pure lead was of a flocculent nature and gray in color. This is evidently an oxidation product. It is well known that bright lead soon changes its color in water solution by oxidation, particularly if a trace of acid be present. ${ }^{4}$

The solutions in which the lead specimens were immersed gradually turned from colorless to a lemon color, the intensity of the color being proportional to the concentration of the acid initially present. At the end of the 24 -day period, during which the specimens were under observation, it was a simple matter to place the solutions in correct order with respect to the initial acid concentration by the color of the liquid; no change of color could be detected in the simple lead-acetate solution.

The appearance of the specimens at the end of the 24 days' immersion is shown in Fig. 6. The specimens which were in the solutions of the greatest acid concentration were very much roughened and embrittled; those in the solutions of less acid 
concentration merely showed evidence of etching on the surface by which the crystalline structure was revealed. In some cases (Nos. 3 and 4 ) the action had been somewhat greater at the sharp corners and edges, so that a rough, crystalline appearance was produced at such points.
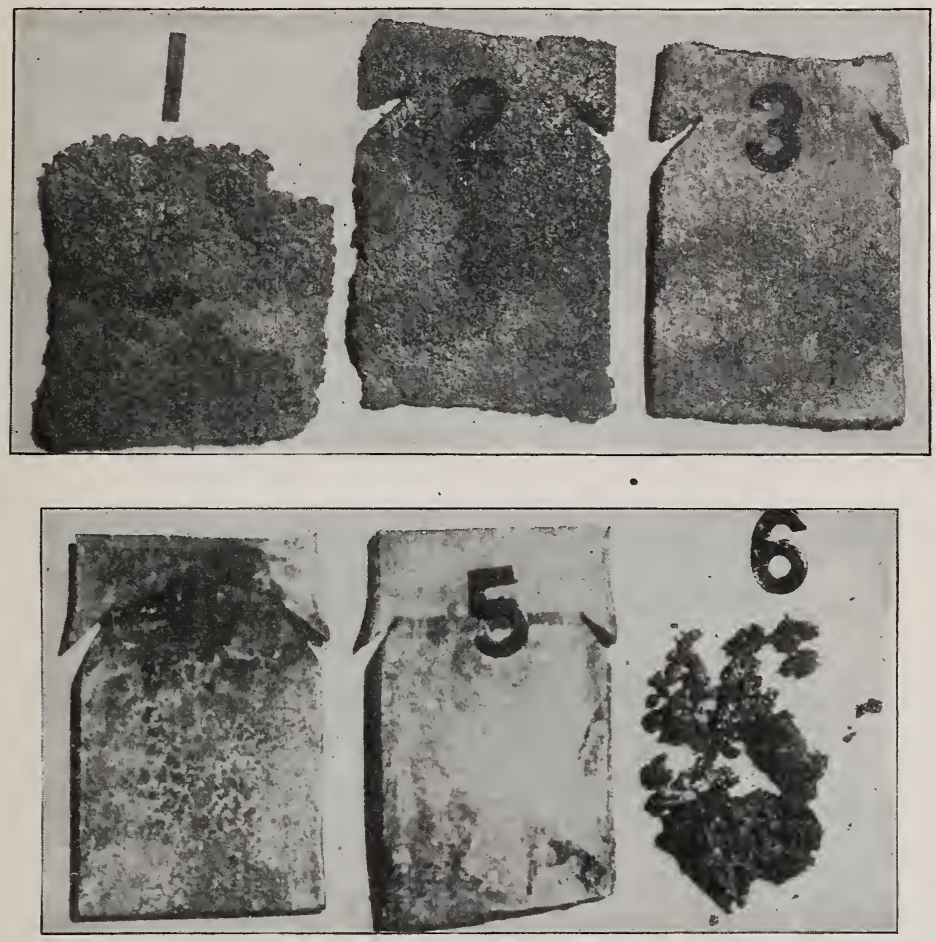

Fig. 6.-Lead immersed in nitric acid solution of lead acetate for 24 day's

\begin{abstract}
Specimen $\mathrm{r}$, pure lead immersed in a solution of lead acetate $(\mathrm{N})$, nitric acid $\left(2 \mathrm{~N}^{\mathrm{T}}\right)$ Specimen 2, pure lead immersed in a solution of lead acetate $(N)$, nitric acid (r.6N) Specimen 3, pure lead immersed in a solution of lead acetate $(N)$, nitric acid $(0.8 N)$ Specimen 4, pure lead immersed in a solution of lead acetate $(\mathrm{V})$, nitric acid $\left(0.5 N^{\mathrm{r}}\right)$ Specimen 5, pure lead immersed in a solution of lead acetate $(N)$

Specimen 6 , commercial lead immersed in a solution of lead acetate $(N)$, nitric acid (r.6 $\left.N^{2}\right)$

All are slightly larger than natural size
\end{abstract}

With specimen No. 4 (immersed in $0.5 N$ acid), a very faint etch pattern on only one side of the sheet was observed, the remainder still showing the marks due to rolling. The specimen immersed in the solution of lead acetate containing "no acid showed no evidence of etching; the surface, here as in the others, was covered with a slight, gray "bloom" which could be easily wiped off. Slight traces of "lead trees" at the sharp corners of the specimens were noted in one case of immersion in lead acetate. 


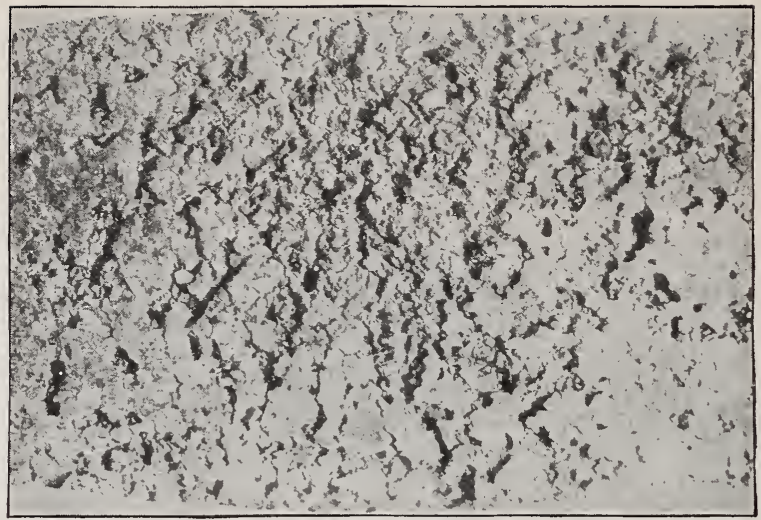

(a)

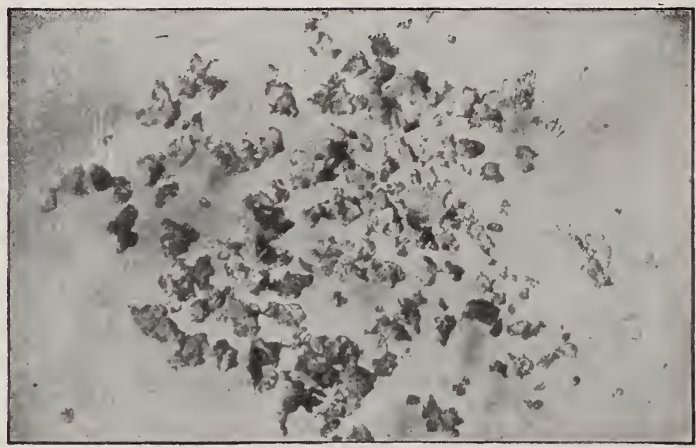

(b)

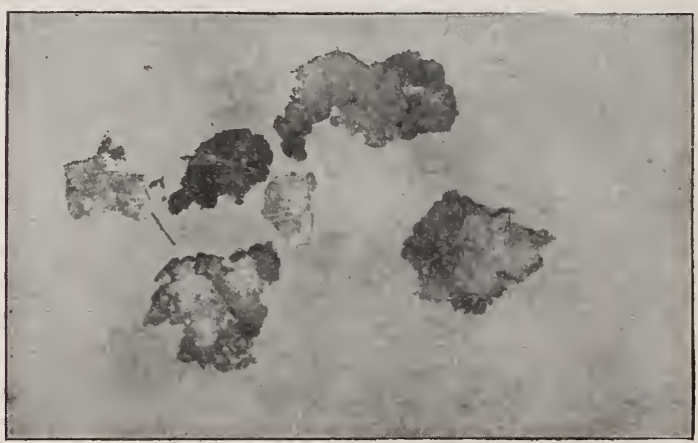

$(c)$

IIG. 7.-Embrittled commercial-lead sheathing

The strip of commercial lead (Table 2) was immersed in a solution of $1000 \mathrm{~cm}^{3}$ water, $400 \mathrm{~g}$. lead acetate and $100 \mathrm{~cm}^{3}$ concentrated nitric acid four days ( 96 hours):

(a) Surface view of specimen, $\times 8$

(b) Crystals which became detached and formed sludge on bottom of flask. $\times 8$

(c) Crystals similar to those of $(b)$ that have been flattened. The crystals still show characteristic properties of lead. $\times 8$ 


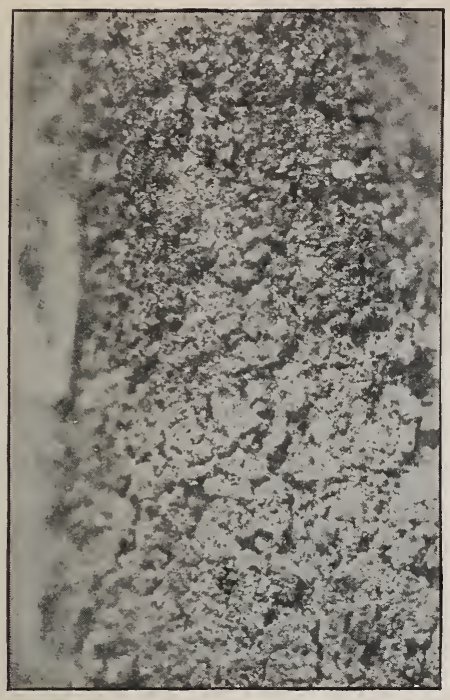

(a)

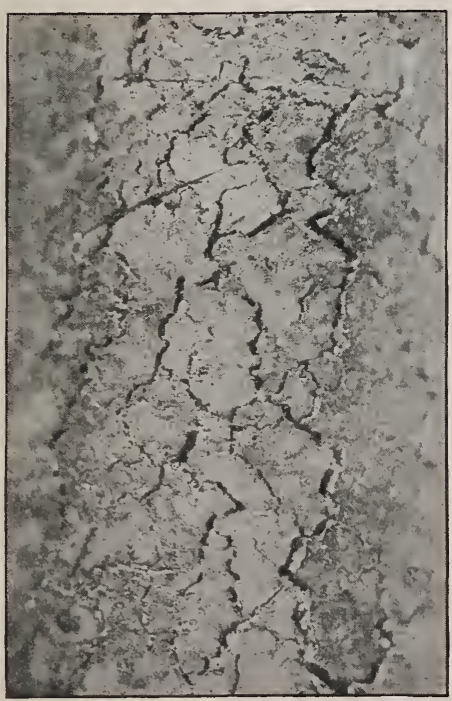

(c)

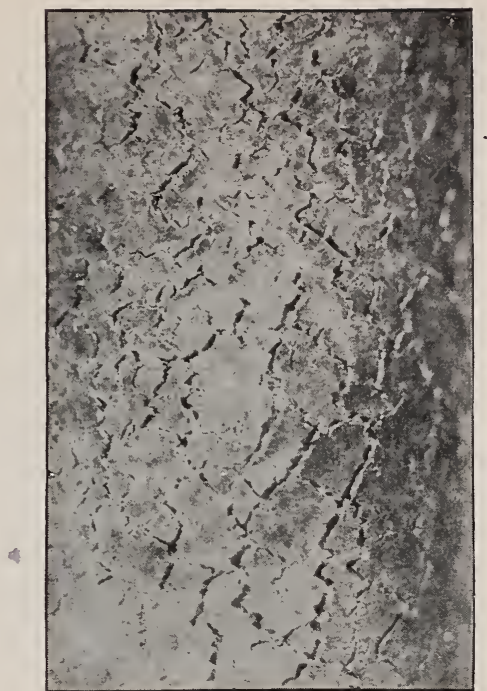

(3)

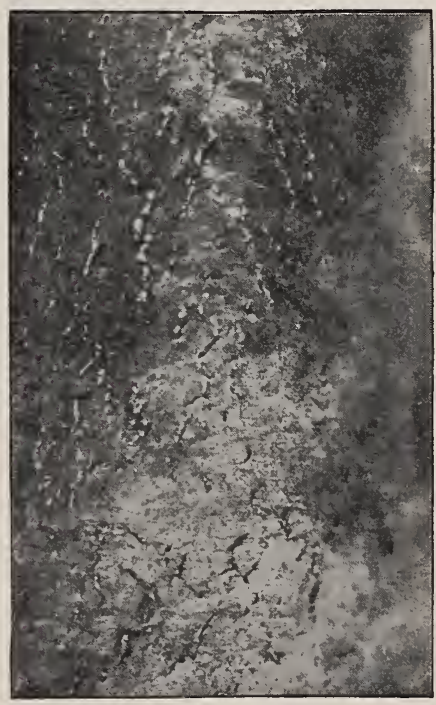

(d)

FIG. 8.-Intercrystalline brittleness induced in pure lead by immersion in nitric acid, solution of lead acetate

(a) Specimen 2, Fig. 6; (b) specimen 3, Fig. 6; (c) specimen 4, Fig. 6; (d) specimen 5, Fig. 6. All have been bent at an angle of approximately $150^{\circ}$ to reveal intercrystalline weakness 
The behavior of the different sheets when bent sharply indicates clearly that a more profound change occurred in the material than was indicated by the appearance of the surface. This is shown in Fig. 8. In each case, including those specimens the surface appearance of which appeared to be suggestive of no appreciable change, the metal cracked and revealed a series of inter-

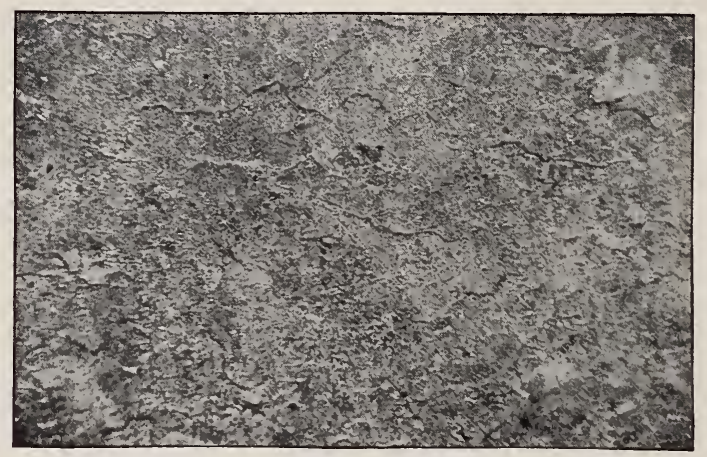

(a)

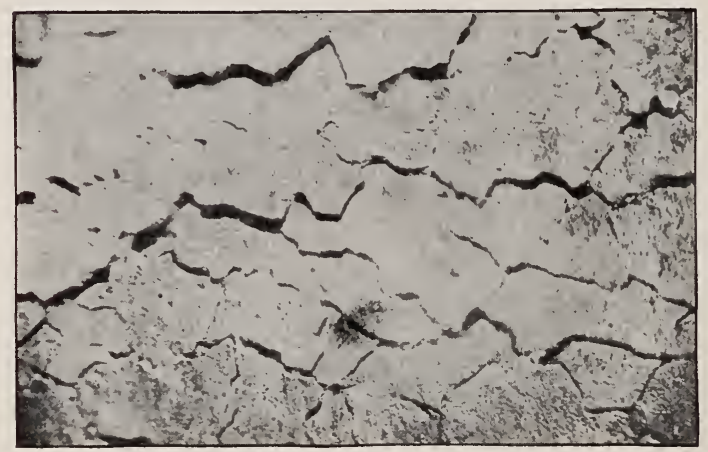

(b)

Fig. 9.-Pure lead showing intercrystalline embrittlement

A sheet of pure lead (Table ${ }_{2}$ ) was immersed in a solution of lead acetate $(N)$ and nitric acid $(0.5 N)$ for to days

(a) Surface view of the specimen after rubbing to remove the slight "bloom" or deposit; unetched. $X_{15}$

(b) Same specimen after bending through $150^{\circ}$. The fissures which are revealed are truly intercrystalline. $X_{I_{5}}$

crystalline breaks, thus indicating that an intercrystalline brittleness of the lead had resulted from the action of the electrolyte. These intercrystalline breaks are best revealed in specimens immersed in lead-acetate solutions containing little or no acid. In the solutions of higher acid concentration the attack of the metal along the crystalline boundaries is great enough, so that the speci- 
men is merely roughened. The preferential attack of lead along the crystalline boundaries during immersion in a solution of lead acetate $(N)$ and nitric acid $(0.5 N)$ for Io days is shown in Fig. 9. The surface has the appearance of being very slightly etched; upon bending, however, wide fissures formed between the crvstals parallel to the direction of bending.

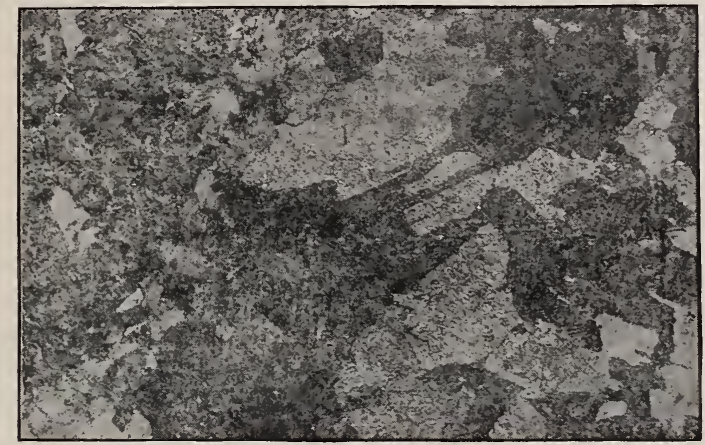

(a)

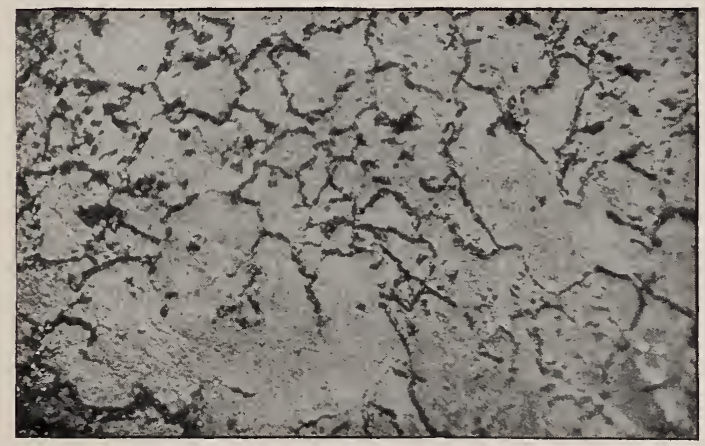

(b)

FIG. Io.-Pure lead showing intercrystalline embrittlement

A sheet of pure lead ( Table $_{2}$ ) was immersed in a solution of lead acetate $(\mathrm{V})$ and nitric acid (I.6N) for 12 days

(a) Specimen after a few minutes' immersion. $\times 8$

(b) Same specimen after I2 days' immersion in the solution. The area shown is not the same as that of $(a)$. Conspicuous fissures have formed around most of the crystals. $X I 5$

The more rapid attack along the crystal boundaries of metal immersed in solutions of high acid concentration is shown in Fig. Io. The lead was immersed for 12 days in a solution of lead acetate $(N)$, nitric acid ( . $6 N$ ).

The results of the immersion of the lead in the lead-acetate solutions are summarized in Table 3 . 
TABLE 3.-Effect of Nitric-Acid Solution of Lead Acetate Upon Lead After 24 Days' Immersion

\begin{tabular}{|c|c|c|c|c|c|c|c|}
\hline No. & $\begin{array}{l}\text { Type of } \\
\text { lead } a\end{array}$ & $\begin{array}{l}\text { Solu- } \\
\text { tion: } \\
\text { Con- } \\
\text { cen- } \\
\text { tration } \\
\text { of nitric } \\
\text { acid in } \\
N \text { solu- } \\
\text { tion of } \\
\text { lead } \\
\text { acetate }\end{array}$ & $\begin{array}{c}\text { Evolution of } \\
\text { gas }\end{array}$ & $\begin{array}{c}\text { Color of solu- } \\
\text { tion }\end{array}$ & $\begin{array}{l}\text { Amount of } \\
\text { "sludge" }\end{array}$ & $\begin{array}{l}\text { Character of } \\
\text { surface } b\end{array}$ & $\begin{array}{l}\text { Behavior upon } \\
\text { bending } c\end{array}$ \\
\hline $1 \ldots$. & Pure.. & $2.0 \mathrm{~N}$ & $\begin{array}{l}\text { Fine bubbles } \\
\text { appear with- } \\
\text { in a few } \\
\text { minutes. }\end{array}$ & $\begin{array}{l}\text { Deep lemon } \\
\text { yellow. }\end{array}$ & $\begin{array}{l}\text { Considerable } \\
\text { deposit; } \\
\text { about } 0.2 \text { of } \\
\text { the speci- } \\
\text { men had } \\
\text { dis inte- } \\
\text { grated. }\end{array}$ & Very rough... & $\begin{array}{c}\text { Broke easily } \\
\text { upon bend- } \\
\text { ing. }\end{array}$ \\
\hline $2 \ldots \ldots$ & ...do... & $1.6 N$ & . do........ & Lemon yellow. & $\begin{array}{l}\text { Slight deposit } \\
(0.02 \mathrm{~g} \text { in } 5 \\
\text { days }) .\end{array}$ & $\begin{array}{l}\text { Rough; a brit- } \\
\text { tle } 1 \text { a y e r } \\
\text { formed on } \\
\text { each side. }\end{array}$ & $\begin{array}{l}\text { Deep, continu- } \\
\text { ous cracks } \\
\text { formed. }\end{array}$ \\
\hline $3 \ldots$. & ...do... & $.8 N$ & $\begin{array}{l}\text { A few very fine } \\
\text { bubbles af- } \\
\text { ter several } \\
\text { hours' im- } \\
\text { mersion. }\end{array}$ & $\begin{array}{l}\text { Light lemon } \\
\text { yellow. }\end{array}$ & $\begin{array}{l}\text { Only a few } \\
\text { is o } 1 \text { a t e d } \\
\text { specks. }\end{array}$ & $\begin{array}{l}\text { Surface was } \\
\text { e } t \mathrm{c} \text { b e d } \\
\text { enough to } \\
\text { show crys- } \\
t \text { a } 11 \text { i } \mathrm{n} \text { e } \\
\text { structure; } \\
\text { the corners } \\
\text { and edges } \\
\text { were much } \\
\text { roughened. }\end{array}$ & $\begin{array}{l}\text { Short, wide, } \\
\text { intercrys- } \\
\text { talline fis- } \\
\text { s u r e s } \\
\text { opened. }\end{array}$ \\
\hline $4 \ldots$. & $\ldots$ do... & $.5 \mathrm{~N}$ & $\begin{array}{l}\text { Yery s ma } 11 \\
\text { is o } 1 \text { a } t \text { e d } \\
\text { b u b b les } \\
\text { seen occa- } \\
\text { sionally. }\end{array}$ & $\begin{array}{l}\text { A slight tinge } \\
\text { of y e } 110 \mathrm{w} \\
\text { could just be } \\
\text { detected. }\end{array}$ & None......... & $\begin{array}{l}\text { Slight"bloom" } \\
\text { on surface; } \\
\text { faint etch } \\
\text { markings } \\
\text { visible. }\end{array}$ & $\begin{array}{l}\text { Fine inter- } \\
\text { crystalline } \\
\text { cracks were } \\
\text { opened. }\end{array}$ \\
\hline $5 \ldots$ & ...do... & $(d)$ & $\begin{array}{c}\text { No bubbles } \\
\text { detected. }\end{array}$ & Colorless.... & ..... do. & $\begin{array}{c}\text { Slight"bloom", } \\
\text { on surface; } \\
\text { no evidence } \\
\text { of etching. }\end{array}$ & $\begin{array}{l}\text { Fine inter- } \\
\text { crystalline } \\
\text { fiss ures } \\
\text { opened. }\end{array}$ \\
\hline $6 \ldots$. & $\begin{array}{l}\text { Com- } \\
\text { mer- } \\
\text { cial. }\end{array}$ & $1.6 \mathrm{~N}$ & $\begin{array}{l}\text { Bubbles oc- } \\
\text { curred with- } \\
\text { in less than } \\
1 \mathrm{~m} \text { in ut e } \\
\text { after immer- } \\
\text { sion. }\end{array}$ & $\begin{array}{l}\text { Deep lemon } \\
\text { yellow. }\end{array}$ & $\begin{array}{l}\text { Most of the } \\
\text { specimen } \\
\text { had disinte- } \\
\text { grated into } \\
\text { "sludge." }\end{array}$ & $\begin{array}{l}\text { Only a few } \\
\text { fragments of } \\
\text { the speci- } \\
\text { men were } \\
\text { left; most } \\
\text { of it was in } \\
\text { the form of } \\
\text { "sludge." }\end{array}$ & . $\ldots \ldots \ldots \ldots \ldots$ \\
\hline
\end{tabular}

\section{ELECTROLYSIS OF LEAD IN CONCENTRATED NITRIC ACID}

A number of attempts were made to produce the spongy lead, noted by Creighton, by means of electrolysis in concentrated nitric acid (sp. gr., I.42). The lead used was the high-grade material listed in Table 2. This was made the cathode of the electrolytic cell, platinum foil being the anode. The lead electrode was 
approximately 4 by $\mathrm{I} \mathrm{cm}$ by $3 \mathrm{~mm}$; a current of 2 amperes was used in most cases, although in some this was increased to $3 \mathrm{am}$ peres. In most cases a volume of electrolyte of $50 \mathrm{~cm}^{3}$ was used.

A copious evolution of gas occurred at the platinum anode when the circuit was closed; this was a colorless gas which turned brown when air was admitted into a tube of it. Evidently it was nitric oxide. A fine stream of minute gas bubbles was also to be seen rising from the lead cathode. This gas apparently dissolves in the concentrated acid. Attempts were made to collect it in a test tube filled with concentrated nitric acid inverted over the cathode. No gas was collected, however, until the action had continued for more than 48 hours and the color of the acid within the inverted tube had changed to a dark green. The gas, as collected, was dark brown in color and evidently was nitrogen peroxide. A white, crystalline substance formed on the lead cathode-lead nitrate. This substance is rather insoluble in the concentrated nitric acid, and collected as a heavy deposit on the cathode and on the bottom of the flask under this electrode.

When the action was allowed to continue for some time (for example, 24 hours), a black, gritty deposit formed upon the platinum electrode. This deposit usually formed after the solution had become rather warm and had evaporated considerably. This was the only substance formed which might be mistaken for an allotropic form of lead. In one case, when the solution evaporated to a very small volume, some of this black deposit was found on the lead cathode as well as on the platinum anode. However, all attempts to reproduce this condition failed.

Chemical analysis showed that the black anode deposit was an oxide of lead. An oxygen content of I 2.95 per cent was found, pure lead peroxide, $\mathrm{Pb} \mathrm{O}$, contains 13.35 per cent oxygen. It is evident that the electrolysis in concentrated nitric acid is complicated by several secondary reactions. The production of nitrogen peroxide at the lead cathode and the lead peroxide at the anode are instances. Examination of the lead cathodes after the action was completed failed to show any pronounced embrittlement of the lead. Examination at intervals during the progress of the action showed that the attack on the metal often was intercrystalline in its nature. This is illustrated in Fig. I I, which shows the surface of the lead cathode at two different stages. The more rapid attack along the crystal boundaries is very evident. That the lead has not been rendered brittle by the electrolytic action is evident upon sharply bending the sheet (Fig. I I $d$ ). 


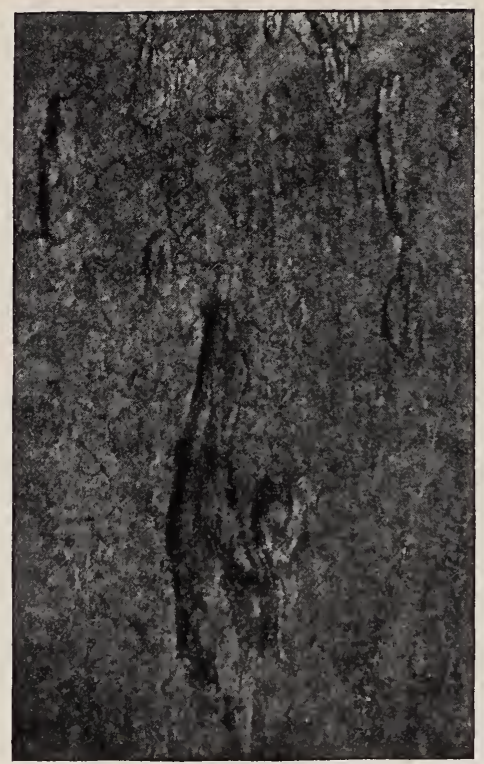

(a)

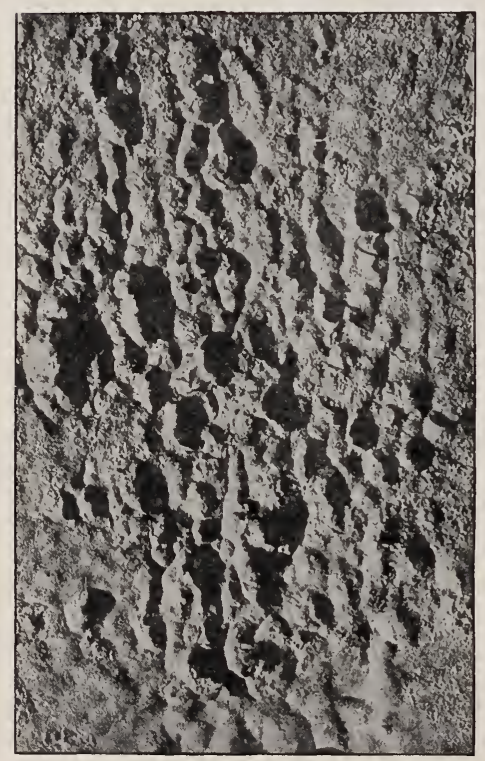

(c)

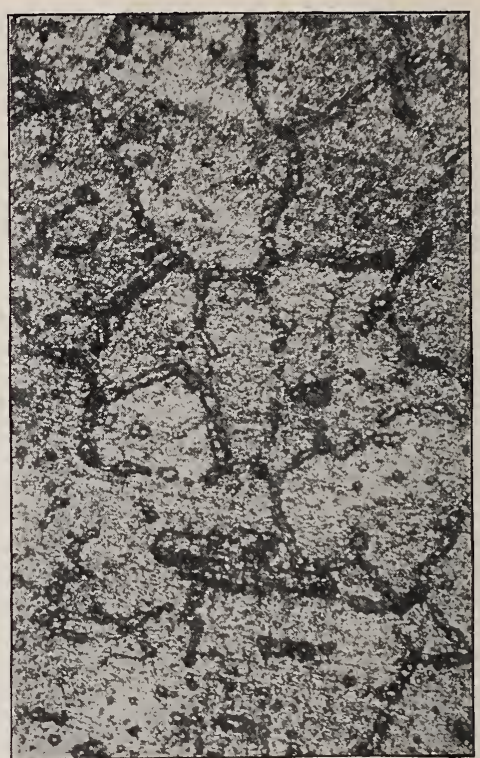

(b)

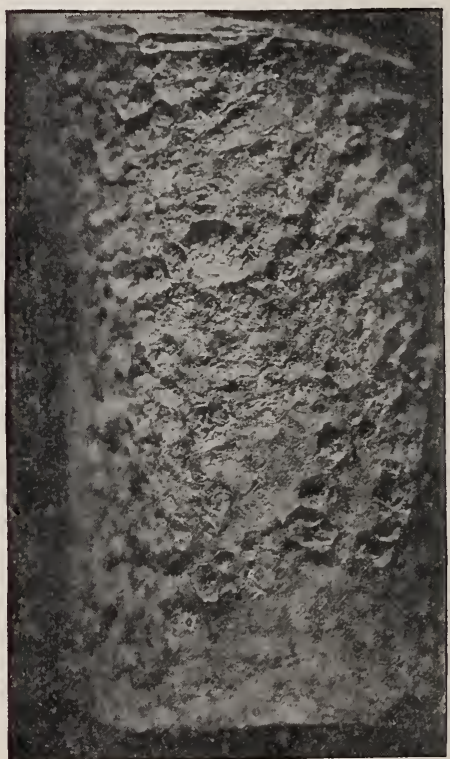

(d)

FIG. II.-Pure lead used as cathode in electrolysis of concentrated nitric acid

(a) Surface view of lead cathode after I 2 hours' treatment; portions of specimen showed a distinct intercrystalline attack. $\times 8$

(b) Same material as $(a)$. The intercrystalline nature of the attack is very evident here. $\quad X_{50}$

(c) Same material after 36 hours' treatment. The nature of the surface suggests that crystals are dissolved bodily after intercrystalline attack has started. $\times_{4}$

(d) Same material as $(a)$, bent at an angle of $180^{\circ}$. Metal has not been embrittled by electrolytic action to any appreciable extent. $\quad \times_{4}$ 


\section{EXPLANATION OF RESULTS}

Most of the impurities which occur in lead are insoluble in the metal. This is true particularly of copper, zinc, iron, nickel, aluminum, and cobalt, which are only slightly miscible even when both metals are in the liquid state. Such impurities, after solidification, will be lodged between the grains of the lead. Tin, antimony, and silver are completely miscible in lead in the molten state, but almost entirely insoluble in the solid state, with the exception of tin. Each of these three elements forms an eutectic series with lead. These, too, will occur between the grains of the metallic lead.

The difference between the solubility of these impurities and that of the pure lead comprising the interior of the crystal accounts largely for the disintegration of the metal by intercrystalline embrittlement when immersed in a weak acid solution. The greater rate of disintegration of the commercial lead as compared with the pure lead is due to the larger amounts of these intercrystalline impurities. The greater solubility of the intercrystalline film of the lead-tin eutectic which must exist in the metal of corroded cable sheath (Fig. 2) as compared with that of the lead itself accounts for the rapid disintegration of this material when immersed in a solution consisting of substances leached out of the surrounding concrete.

It is to be concluded from the results of the experiments made that the so-called allotropic or gray lead described by Heller represented only a granular condition of the ordinary form of lead, the granulation having been brought about by the action of the electrolyte used, primarily the nitric acid, upon the intercrystalline impurities. No evidence of allotropy could be obtained in the experiments on very pure lead carried out in the manner described by Heller, although unmistakable evidence of intercrystalline brittleness was. secured. The attack of the intercrystalline metal in the high-grade lead by solutions of neutral lead acetate is in all probability to be partly ascribed to the difference in the electrolytic solution potential of the "amorphous intercrystalline cement" as compared with the metal of the interior. To this is to be added the effect of the slight intercrystalline impurities. The precipitation of lead from the solution in the form of "lead trees" in such experiments may be taken as one line of evidence. The change in density of lead specimens immersed in lead-acetate solutions, noted by Cohen and Helderman, may be ascribed to an accompanying oxidation along the grain boundaries, such as 
readily occurs in water or weak aqueous solutions on freshly exposed surfaces of lead. However, this explanation does not completely account for all the changes in density noted. No evidence of embrittlement by means of electrolysis could be obtained, nor was any product formed, other than a deposit of lead peroxide upon the anode, which might be mistaken for an allotropic form of lead.

It is to be concluded that the forms previously described as allotropic lead were only a granular condition of the ordinary form brought about by intercrystalline embrittlement, accompanied, perhaps, by slight oxidation.

\section{SUMMARY}

I. A type of deterioration of lead which renders the metal weak, brittle, and capable of being crumbled easily into grains is described. The deterioration occurs as a result of corrosion during service; the attack on the metal is localized along the crystal boundaries, and the brittleness produced is truly intercrystalline in its nature.

2. Practically all of the commonly occurring impurities in lead are insoluble in the solid state and are to be found lodged between the grains of the lead. The intercrystalline brittleness is due largely to the behavior of these impurities when the metal is immersed in an electrolyte.

3. Specimens of very pure lead were treated in the manner described by previous investigators for the production of the allotropic form of lead. No evidence was obtained to justify the claim that lead may exist in an allotropic state analogous to the well-known gray tin.

4. The forms of lead previously described in the scientific literature as allotropic states appear to be due to an intercrystalline attack by the electrolyte, immersion in which was necessary to bring about the allotropic change. The rate at which the so-called allotropic transformation occurs is largely a function of the purity of the lead and the acidity of the electrolyte in which the metal is immersed.

The author wishes to acknowledge the very efficient help of J. F. T. Berliner in the many examinations necessary in the course of the investigation.

WASHINGTON, November 13, 1919. 